\title{
Adapting MAIN to Brazilian Portuguese
}

\author{
Laís Vitória Cunha de Aguiar \\ University of Brasília (UnB)
}

\section{Micaela Nunes Martins dos Reis}

University of Brasília (UnB)

\begin{abstract}
A translation process is often seen as only a simple code exchange, but, in fact, it always requires an adaptation of terms, expressions, and structures, which is not exactly straightforward. This paper describes the process of translating and adapting the Multilingual Assessment Instrument for Narratives (LITMUS-MAIN) to Brazilian Portuguese. A brief description of the project, concerning both historic and linguistic aspects, was done in order to emphasize the cultural and linguistic challenges faced during the process.
\end{abstract}

\section{Introduction}

The Language Impairment Testing in Multilingual Settings - Multilingual Assessment Instrument for Narratives (LITMUS-MAIN, henceforth MAIN; Gagarina et al., 2012, 2015) is a tool developed within the COST Action IS0804 Language Impairment in a Multilingual Society: Linguistic Patterns and the Road to Assessment (2009-2013) by an international team of researchers, and which was then revised in 2019 (Gagarina et al., 2019). The instrument was developed to assess narrative skills in bilingual children aged 3 to 10 years in their two languages.

Brazil is currently facing a situation where a large number of refugee families are coming to the country, especially from Venezuela. Instruments assessing the language development of bilingual children, including those from refugee families, do not yet exist. In order to be able to assess the children's language skills, both in Brazilian Portuguese, the national language of Brazil, and in their home languages, using the same type of assessment instrument, we have adapted MAIN for Brazilian Portuguese. The results of such assessments can help disentangling children with developmental language disorder (DLD) from children with typical development. We also expect such assessments to help parents gain knowledge about how their children can 
improve the language skills, be it in Portuguese or their mother tongue. A narrative instrument allows for assessment of specific narrative aspects and also gives a holistic picture of the child's language skills. A Brazilian Portuguese version of MAIN would therefore be an important addition to the tools available to assess children speaking this language.

This paper gives a brief description of the Brazilian Portuguese language and outlines how MAIN was translated and adapted into Brazilian Portuguese including some insights which emerged from the experience of translating and adapting the narrative assessment tool.

\section{A short description of the Brazilian Portuguese language}

The Portuguese language, as a Romance language, has Latin roots. In 218 A.D, when the Roman Empire reached the Iberian Peninsula, which is currently where the territory of Portugal is located, most of the people living there were forced to adopt Latin as their main language. However, the Latin brought by the Romans was not the classical Latin, written and spoken by the upper-class population of Rome, but instead the "Vulgar Latin" spoken by the common people. In 711 A.D, the Arabs conquered the Iberian Peninsula and remained there for seven centuries. As a result of the contact of Latin and Arabic with the existing dialects of the region, a new language emerged, the Galician-Portuguese, which in the 13th century became the Portuguese language.

Brazilian Portuguese, the variety of Portuguese spoken in Brazil, has around 200 million speakers. It differs from the variety of Portuguese spoken in Portugal due to influence from indigenous languages and from the immigration to Brazil after the second world war. For example, regarding phonological aspects, there are striking differences in terms of pretonic vowels in some regions of Brazil, in which raising of the vowels /e/ and /o/ to /i/ and /u/ occur, such as in the pronunciation of the words menino 'boy' and dormir 'sleep'. In the variety spoken in Portugal, this type of linguistic phenomenon does not occur.

When the Portuguese arrived in 1500, there were already 2 million people living in Brazil (Ribeiro, 1957), but in only 70 years of colonization, the indigenous population decreased to 200,000. There has also been a large decrease in the number of languages spoken in Brazil: initially around 1,000 languages were spoken, but this number has since decreased by $80 \%$ (IPEA, 2011). There are now only 274 languages spoken by around 800,000 people of 305 different ethnicities (IBGE, 2010).

The Portuguese language became dominant in Brazil only around the 18th century. In 1757, the use of another language was forbidden by a decree made by Marquis of Pombal's Directorate (Garcia, 2007). The decree was revoked 41 years later, but given the fact the Portuguese missions had been trying to erase the indigenous languages from the daily lives of the Brazilian population since they arrived, the restrictions over indigenous languages were further sustained in a cultural way. As most people living in Brazil did not speak Portuguese, even with the Portuguese attempt to erase the indigenous languages, an exchange language was created. This language was called the 'Brasílica Language' (Góis \& Martins, 2019). Later, this language became the basis for the standard Brazilian Portuguese. While Brazilian Portuguese 
contains many indigenous words, the grammar differs only slightly from the Portuguese spoken in Portugal.

Another important influence on Brazilian Portuguese were the African languages: Portuguese as a second language for the Africans brought many linguistic innovations, even in grammar, such as the sentence construction oriented towards the subject. This structure (known as locative inversion), is common in many languages that belong to the Bantu language family, spoken in Africa, and it is commonly found in Romance languages.

\section{The process of adapting MAIN to Brazilian Portuguese}

The work of translating and adapting MAIN to Brazilian Portuguese was shared among five students of linguistics of the University of Brasília, including the two authors of this paper. The five people involved in the adaptation process come from different parts of Brazil, where different varieties of Brazilian Portuguese are spoken. This made it necessary to check the translation carefully and standardize the terms used throughout the text. Concerning grammar, the scoring sheet was a challenge because the English grammar differs from the Brazilian Portuguese one, so it was crucial be sure about the aim of each aspect that was to be scored to be certain that we did the right translation. Below, the specific challenges are presented in detail.

The warming-up part of MAIN, which describes how to start the interaction with the child, presented us with the challenge of the best translation of the main term 'warming-up', as some of us translated it as aquecimento 'lit. warming-up', but in Portuguese this term is mainly used to describe physical exercises, e.g. going to the gym and starting exercises with a warming up. After discussion, it was decided to use the word preparação 'lit. preparation', because we wanted to make it clear that this concerned preparing the child for the MAIN task, not a physical exercise.

Another challenging term was the word counterbalancing which has two equivalents in Brazilian Portuguese, contrapeso 'lit. counterbalancing' and equilíbrio 'balancing'. These two words, although they have similar meanings, are used in different contexts. After a lengthy discussion contrapeso was chosen, because it better suits the experimental context of the task. Another complicated word was deictic. Since there is no direct equivalent in Brazilian Portuguese to this word, it was decided to include an explanation of its meaning: referências que limitem a experiência em relação a cada contexto específico, como indicadores de espaçoaqui, lá-, e tempo 'references that might limit the experience in relation to each specific context, such as time, place and space.'

The translation of acronyms, such as IST (Internal State Terms), also posed an issue. We were not able to find any existing term for Internal State Terms in Portuguese. For this reason, we translated it literally and explained its meaning in the text. In the same way, the term experimenter effects caused a problem, because Brazilian Portuguese does not possess an equivalent to this word. Therefore, it was decided to add the following definition of this concepts: efeitos da sua expectativa em relação à experiência 'effects of your expectation in relation to the experience.' 
In terms of the vocabulary used in the story scripts and comprehensions questions, writing in a way that would not exclude any child because of the lexical differences between the regions of Brazil was the most difficult part, and the one discussed most extensively in our team. Terms like 'little bird', and 'baby goat' are not frequently used by Brazilian-Portuguesespeaking children; instead diminutives are used, e.g. pássaro 'bird' becomes passarinho 'little bird', and cabra 'goat', becomes cabrinha 'little goat-FEM' or cabritinho 'little goat-MASC'. Additionally, in the northeast region, the word cabra is used to describe someone who is fool, or silly. For this reason, it was decided to use cabrito 'goat-MASC' instead of cabra 'goatFEM' with its diminutive version cabritinho 'little goat-MASC', for the goat and the baby goats, respectively. As all nouns denoting animals are explicitly marked as either feminine or masculine in Portuguese (e.g. cabra 'goat-FEM', cabrito 'goat-MASC') for each animal in the stories, it was necessary to make a choice between the masculine and feminine form of the word. In the end, our decision was based on what was the most familiar word for children. For this reason, cabritinho 'little goat-MASC' was used for the baby goats and passarinho 'baby bird-MASC' for the baby birds. The cat, dog, mouse, and fox were therefore translated as gato 'cat-MASC', cachorro 'dog-MASC', rato 'mouse-MASC', and raposa 'fox-FEM'.

Finally, the issue of how formal the language of the comprehension questions should be was discussed. In Brazil, children are usually addressed using the informal register, and the MAIN comprehension questions should therefore be asked using this register. For interrogatives, Portuguese use the same structure as in affirmatives, i.e. SVO word order. The differences between affirmatives and interrogatives are in the tone used and in the use of an interrogative pronoun (como 'how', quando 'when', onde 'where', quem 'who', quanto 'how much', $o$ que 'what'). Regarding imperative sentences, which were used to encourage the child to carry on with the story, in the formal register, the structure is verb+clitic, e.g. conte-me a estória 'tell me the story', but here we chose the informal one, with the structure pronoun+verb, e.g. me conte a estoria 'tell me the story' (lit. 'to me tell the story').

\section{Conclusion}

In this paper, we have described some linguistic, historical and social aspects of Brazilian Portuguese and outlined the main challenges in the process of translating and adapting MAIN to this language. It is undeniable that translating MAIN was a challenging task, but since we were especially careful during this process and united our knowledge of dialectal variation between different regions of Brazil, we strongly believe that we have achieved the intended goal. From now on, we aim to use MAIN in Brazil and improve the translation and adaptation, if necessary, based on reports from pilot testings from other researchers. 
Gagarina, N., Klop, D., Kunnari, S., Tantele, K., Välimaa, T., Balčiūnienė, 1., Bohacker, U., \& Walters, J. (2012). MAIN: Multilingual Assessment Instrument for Narratives. ZAS Papers in Linguistics, 56.

Gagarina, N., Klop, D., Kunnari, S., Tantele, K., Välimaa, T., Balčiūnienė, 1., Bohacker, U., \& Walters, J. (2015). Assessment of Narrative Abilities in Bilingual Children. In S. Armon-Lotem, J. de Jong, \& N. Meir (Eds.), Assessing multilingual children disentangling bilingualism from language impairment (pp. 243-269). Bristol: Multilingual Matters.

Gagarina, N., Klop, D., Kunnari, S., Tantele, K., Välimaa, T., Balčiūnienė, 1., Bohacker, U., \& Walters, J. (2019). MAIN: Multilingual Assessment Instrument for Narratives - Revised. ZAS Papers in Linguistics, 63.

Garcia, E.F. (2007). O projeto pombalino de imposição da língua portuguesa aos índios e a sua aplicação na América meridional. Tempo, 12(23), 23-38.

Góis, M. L. S., \& Martins, A. M. S. (2019). O Tupi antigo no português: Algumas questões sobre história, identidade e ensino de línguagem [The Ancient Tupi in Portuguese: A few issues on history, identity, and language teaching]. Trabalhos em Linguística Aplicada, 58(1), 422-440.

IBGE (2010). 2010 Population Census. Brasília: Brazilian Institute of Geography and Statistics (IBGE).

IPEA (2011). Retratos - Somos 210 Brasis. Brasília: Institute of Applied Economic Research (IPEA).

Ribeiro, D. (1957). Culturas e línguas indígenas do Brasil. Rio de Janeiro: Centro Brasileiro de Pesquisas Educacionais. 